\title{
Gestão das águas e sustentabilidade: desafios globais e respostas locais a partir do caso de Seropédica, na Região Metropolitana do Rio de Janeiro
}

\author{
Water management and sustainability: global challenges \\ and local responses from the case study of Seropédica, \\ Metropolitan Region of Rio de Janeiro
}

Denise de Alcântara Adriana Soares de Schueler

\section{Resumo}

Este artigo versa sobre o desenvolvimento territorial e a questão hídrica da região abrangida pela Bacia Sedimentar de Sepetiba, onde se situa Seropédica, município da Região Metropolitana do Rio de Janeiro. A partir de investigação tipomorfológica na escala regional, busca enfatizar sua relação com o abastecimento de água para a RMRJ; a presença do Aquífero Piranema, recurso hídrico em permanente risco ambiental devido às atividades de extração mineral; a expansão urbana/industrial em consequência dos grandes investimentos em curso; e a infraestrutura urbana precária, especialmente saneamento e drenagem pluvial. São apresentados, na escala regional, dados quali-quantitativos sobre potencialidades e fragilidades do território e, na local, propostas de intervenções e boas práticas para mitigação dos problemas hídricos verificados nos núcleos urbanizados.

Palavras-chave: crescimento urbano; desenvolvimento sustentável; drenagem pluvial; Aquífero Piranema; Seropédica.

\begin{abstract}
This paper addresses the territorial development and the water issue of the region covered by the Sepetiba Sedimentary Basin, where the municipality of Seropédica is located, in the Metropolitan Region of Rio de Janeiro. From a typo-morphological investigation on the regional scale, it seeks to approach the basin's relationship to the water supplying for the Metropolitan Region of Rio de Janeiro; the presence of the Piranema Aquifer, which has been in permanent environmental risk due to sand extraction activities; the urban/industrial growth due to investments in course; and the precarious urban infrastructure, especially sewage and rainwater drainage systems. Qualitative and quantitative data on the potentialities and fragilities of the territory are presented in the regional scale. Locally, we propose interventions and good practices to mitigate the water problems that have been verified in the urban nuclei.
\end{abstract}

Keywords: urban growth; sustainable development; rainwater drainage system; Piranema Aquifer; Seropédica. 


\section{Introdução}

A expansão urbana em municípios e áreas periféricas da Região Metropolitana do Rio de Janeiro (RMRJ) é hoje uma realidade inexorável, em função dos grandes investimentos infraestruturais e industriais que vem sendo implantados, tais como o Arco Metropolitano, a expansão do Porto de Itaguaí e o Complexo Petroquímico em Itaguaí (Comperj) (Oliveira et al., 2012). Como consequência, desencadeiam-se outros processos econômicos que atraem, pela geração de empregos e pelas oportunidades criadas, um novo contingente populacional e outros investimentos correlatos.

A Região Metropolitana do Rio de Janeiro compreende vinte e um municípios, ${ }^{1}$ sendo seu principal núcleo e polo de atração localizado no município do Rio de Janeiro, espaço luminoso (Santos, 2005) que recebe historicamente os maiores investimentos e atenções do poder público. Nos demais municípios ou espaços periféricos, ou opacos, em geral não se prevê nem se realiza o devido planejamento ou ordenação territorial que possa dar vazão de forma equilibrada e minimamente sustentável ao crescimento econômico.

Em sua porção oeste, a RMRJ se sobrepõe à região hidrográfica do Guandu, que incorpora a Bacia Sedimentar de Sepetiba, onde estão situados os municípios de Seropédica e Itaguaí. 0 crescimento nesses municípios vem sendo potencializado, tanto em função de grandes investimentos - especialmente a inserção de um anel rodoviário metropolitano e a expansão portuária e industrial em Itaguaí - quanto devido à existência de vasto estoque de terras, caracterizadas como espaços livres de edificações (Magnoli, 2006) ou urbanização ainda disponíveis. Aliam-se a esses fatores, as restrições mínimas ou quase inexistentes quanto à forma ou direcionamento de ocupação territorial ou urbana, conforme indicam estudos sobre os Planos Diretores Participativos desses e demais municípios da RMRJ (Monteiro, 2010).

Cenários prospectivos produzidos para os municípios atravessados pela rodovia logística - o Arco Metropolitano do Rio de Janeiro - desenvolvidos por grupos acadêmicos envolvidos com estudos sobre seus impactos socioambientais e econômicos (Tângari et al., 2012) em especial, Itaguaí e Seropédica (Alcantara, 2014), sugerem o estabelecimento de vetores de expansão e ocupação, bem como os riscos ambientais advindos de um crescimento não estruturado.

A fragilidade ambiental verificada na Bacia Sedimentar de Sepetiba, por onde correm as águas do Rio Guandu e se esconde no sobsolo o Aquífero Piranema, denota a importância e urgência de estudos específicos e de ações de planejamento, bem como a definição de instrumentos urbanísticos, no que concerte ao uso e ocupação do solo, direcionados à sua proteção e manejo sustentável. Toda e qualquer intervenção sobre o território produzirá impactos sobre esses importantes recursos hídricos e seus afluentes, assim como intervenções inapropriadas poderão impactar a drenagem pluvial, o saneamento básico e mesmo o abastecimento de água para toda a RMRJ. Tais impactos são amplificados em função do lençol freático superficial característico na região e pelas baixas altitudes de áreas urbanizadas ou com potencial de ocupação e apropriação. 
Estudos recentes (Oliveira et al., 2012), assim como o Plano Diretor Municipal (Seropédica, 2006) vislumbram essa região como um futuro polo logístico por sua proximidade com o Complexo Portuário de Itaguaí. 0 território e a paisagem de Seropédica passam atualmente por um intenso processo de transformações de uso e ocupação em função da recente inserção de rodovia logística que, junto com a expansão em curso do complexo portuário em Itaguaí, catalisam e impulsionam o crescimento das atividades industriais, retro portuárias e imobiliárias no município. Entretanto, a região sofre a ameaça de uma potencial ocupação extensiva e descontrolada de seus espaços livres, bem como de um adensamento excessivo e desordenado dos núcleos urbanizados, ambos desprovidos de qualidade socioambiental.

0 presente estudo configura-se um diálogo e principais desdobramentos das pesquisas "Morfologia da Paisagem e Transformação de Usos: análise, categorização e construção de cenários prospectivos do Sistema de Espaços Livres em Seropédica", 2 desenvolvida no âmbito do Gedur e "0 caminho das águas em Seropédica: soluções de baixo custo", desenvolvida no âmbito do grupo EcoCidades, ambos $^{3}$ sediados na Universidade Federal Rural do Rio de Janeiro. Metodologicamente, a análise tem uma abordagem transescalar, desde a escala macro à micro ou local. Na macroescala, a investigação abrangente sobre a inserção na RMRJ do município em foco considera os aspectos geobiofísicos e a complexidade hídrica relacionadas a Bacia Sedimentar de Sepetiba. 0 foco na microescala - ou local busca identificar e analisar as principais questões hídricas e visa à proposição de boas práticas de gestão urbana, nesse caso em relação à drenagem superficial, como um dos primeiros passos em direção a mitigar os impactos sobre corpos d'água existentes.

Seguindo a mesma lógica do estudo, o presente artigo se estrutura a partir dessas duas abordagens dimensionais. Inicialmente, contextualiza o objeto de estudo na macroescala a partir dos estudos técnicos e acadêmicos desenvolvidos e compartilhados no âmbito do grupo de pesquisas. Na segunda parte, contribui com a proposição de soluções adequadas ambientalmente e viáveis economicamente para o problema da drenagem pluvial, de modo que possam ser aplicadas tanto local quanto regionalmente.

Como objetivo maior e mais abrangente das pesquisas vinculadas, intenciona-se promover o estabelecimento de diretrizes de planejamento participativo para a revisão do Plano Diretor Municipal e colaborar em sua revisão e na elaboração e inclusão de instrumentos urbanísticos e de boas práticas na gestão municipal, considerando, em uma etapa posterior da pesquisa em andamento, a integração e intercâmbio de atores sociais, acadêmicos e institucionais no âmbito dos processos de planejamento e projeto.

\section{Aspectos geobiofísicos da Bacia Sedimentar de Sepetiba}

0 estabelecimento de ações para mitigar, minimizar ou mesmo evitar a destruição dos recursos naturais de uma região demanda 0 entendimento sistêmico tanto dos aspectos relacionados ao crescimento econômico, ao 
desenvolvimento e à economia regulatória (Harvey, 2011), quanto aos princípios socioambientais e culturais, que envolvem migração e movimentos sociais, pegada ecológica, biofilia, entre outros (Forman, 2008). Assim, considerando o suporte físico da Bacia Sedimentar de Sepetiba como recorte, busca-se aplicar o conceito de ecologia da paisagem para a análise e estudo dessa porção do mosaico territorial fluminense em duas escalas de análise - a macro ou regional, mais abrangente, e a micro, ou local, assim que integra os padrões espaciais da escala humana.

Com base na fundamentação acima e a partir do recorte metodológico estabelecido, o território em franca transformação de Seropédica é analisado de acordo com parâmetros relacionados aos sistemas de espaços livres, tanto urbanos quanto periurbanos (Tângari et al., 2013). A maior abrangência da escala macro, ou regional, sobre a bacia sedimentar, onde o município se insere, configura-se pelos sistemas e redes de fluxos, numa abordagem estrutural e quantitativa. Nesse sentido, foram identificadas e categorizadas as unidades de paisagem, os aspectos geobiofísicos (corpos hídricos, relevo, cobertura vegetal), os fluxos e conectividades, os núcleos urbanos, suas formas de uso e ocupação, e os espaços livres e os processos de transformação em curso na região.

0 foco na escala micro aproxima-se de recortes locais específicos relacionados a questões de escoamento, drenagem e absorção das águas fluviais e pluviais, que, por sua vez, ameaçam os grandes corpos hídricos da região - o Rio Guandu e o Aquífero Piranema. A caracterização, mapeamento e análise morfológica da paisagem desse compartimento paisagístico visam uma avaliação aplicável aos sistemas urbanos e periurbanos e suas condicionantes físico-ambientais.

Em termos geomorfológicos, Seropédica é constituída a oeste pela Serra do Mar e a sudeste pela baixada da Bacia Sedimentar Cenozóica Flúvio-Marinha de Sepetiba. As duas grandes unidades de relevo - as encostas da Serra do Mar e a planície - se constituem nos dois principais compartimentos que delimitam o mosaico vegetacional da região, fundamentalmente distintos e heterogêneos no que se refere à biodiversidade. Nas encostas da Serra do Mar, a cobertura vegetal é formada pela Floresta Ombrófila Densa Submontana - ecossistema que ocorre as serras litorâneas e nos maciços isolados, sobre rochas do embasamento cristalino e rochas ígneas. A orientação de sua formação rochosa é de fundamental importância na composição da vegetação e, consequentemente, no abastecimento dos rios (Montezuma e Cintra, 2012).

A grande extensão da planície possibilita o espraiamento das águas dos diversos rios e córregos que drenam a região, atenuando seu potencial erosivo, controlando e redistribuindo as águas e os sedimentos carreados das partes mais elevadas. A topografia típica de baixada é constituída por areais e pântanos, fundindo-se ao território Itaguaí, similar, onde surgem brejais e mangues estendendo-se até a Baía de Sepetiba. Em seu processo de formação, a bacia configurava-se em um grande pântano, e seus morros visualmente se completavam como os da Serra do Mar. Com a ação do intemperismo, as rochas foram se desfazendo, e esses pequenos fragmentos da rocha, ou solo em formação, soterraram o pântano, ao mesmo tempo em que os morros foram perdendo material, reduzindo sua altura e, consequentemente, 
formando as várzeas e morrotes característicos de Seropédica. 0 solo tem sua camada mais superficial arenosa de pouca espessura, o que promove a rápida absorção da água da chuva, porém, com uma rápida saturação, pois o lençol freático é bastante raso. Abaixo da camada arenosa há uma camada espessa de solo argiloso, de baixa permeabilidade.

Sobre os vastos espaços livres ainda presentes na região em sua parte plana ou de baixada, predominam as atividades agropastoris, os campos e as forrações baixas, sendo raras as áreas densamente florestadas. É Importante aqui destacar a presença da unidade de conservação Flona Mário Xavier (criada pelo Decreto 93.369, de 1986), um pequeno (495,99 ha), porém importante exemplar de bioma de Mata Atlântica, caracterizado como Floresta Ombrófila Densa das Terras Baixas, localizada próxima à confluência das rodovias BR-465 (antiga rodovia Rio-São Paulo) e BR-116, a Via Dutra. Ainda que apenas um pequeno fragmento florestal, sofreu impacto direto do Arco Metropolitano, que seccionou a floresta e seus corpos hídricos em seu traçado. A existência de um anfíbio raro (Physalaemus soaresi) que habita seus brejais chegou a atrasar as obras, mas não impediu sua inauguração em julho de 2014.

Mais de $85 \%$ do território do município de Seropédica constitui-se de espaços livres de urbanização e de edificações (Magnoli, 2006; Tângari et al., 2009). Os assentamentos urbanos surgem de forma rarefeita, concentrados em poucos núcleos fragmentados, descontínuos e com baixa densidade construtiva. Sua ocorrência é principalmente nas partes planas e baixios. Tais núcleos conectam-se por meio de rodovias que atravessam e fragmentam 0 território. A BR-465 (antiga rodovia Rio-São Paulo) configura-se como eixo estruturador principal. As rodovias BR-116 (Rodovia Presidente Dutra) e RJ-099 (Reta de Piranema) complementam o quadro de redes viárias que dilaceram a região. Esse aspecto é agravado com a inserção do Arco Metropolitano (RJ-109 ( BR-493), mais um elemento de fragmentação e ruptura socioespacial (Figura 1).

Quanto aos dados climáticos, a região classifica-se como de clima tropical quente (temperatura média superior a $18^{\circ} \mathrm{C}$ ), sub-quente (entre $18^{\circ}$ e $15^{\circ} \mathrm{C}$ ) e subtipo úmido (1 a 3 meses secos). A precipitação pluviométrica média anual atinge $1.224,9 \mathrm{~mm}$, com os maiores valores ocorrendo no período de novembro a abril (meses mais quentes), com médias mensais variando entre 109,2 mm (abril) e 196,1 mm (janeiro). Nos demais meses, 0 índice médio varia entre 30,7 mm e 93,6 mm (outubro). A evaporação anual total média de $1.352 \mathrm{~mm}$, superando a altura pluviométrica total. 0 maior valor médio obteve-se no mês de janeiro (123 mm) e o menor em abril (91 $\mathrm{mm}$ ). 0 balanço hídrico apresenta-se positivo nos meses de janeiro a maio e negativo entre maio e outubro. De outubro a dezembro não apresenta perda nem ganho de água. 0 quadro a seguir apresenta valores médios mensais de precipitação, temperatura e evapotranspiração. Vale salientar que os dados da precipitação e temperatura representam a média de três determinações realizadas às 09h00, $15 \mathrm{~h} 00$ e $21 \mathrm{~h} 00$, seguindo a própria metodologia do Inmet. 0 balanço hídrico é apresentado, tendo sido calculado pelo INMET, utilizando o método de Thornthwaite e Mather (Schueler, 2005). (Figura 2) 
Figura 1 - Configuração geobiofísica de Seropédica.

Em branco e tons claros: espaços livres de urbanização consistindo de áreas planas com baixa forração vegetal, pastagens ou atividades agrícolas; em tons mais escuros: aglomerações urbanas consolidadas ou em consolidação

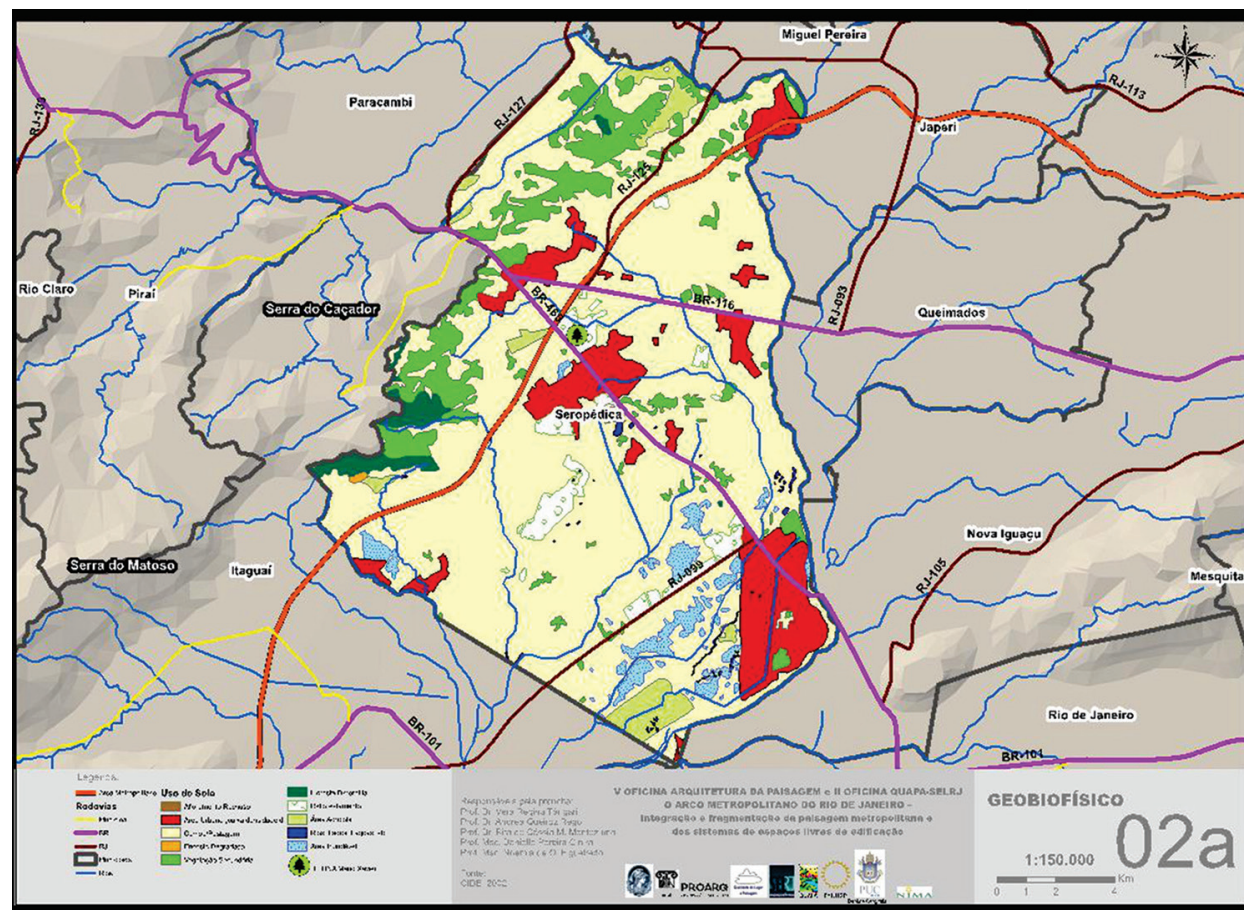

Fonte: Acervo SEL-RJ.

Figura 2 - Gráfico do balanço hídrico mensal em Seropédica, calculado a partir de série histórica climática de 30 anos

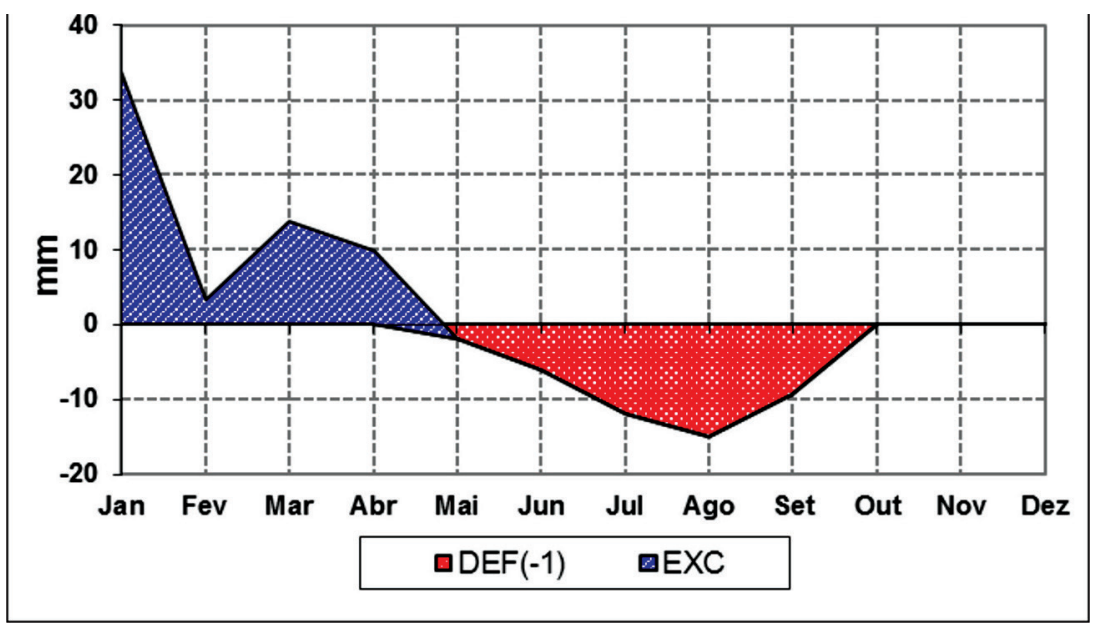

Fonte: INMET. 
O Aquífero Piranema, apesar de não visível na paisagem, e por muitos sequer conhecido, representa um valioso recurso hídrico tanto para a região de influência direta, bem como para toda a RMRJ. Situado geologicamente na região hidrográfica do Guandu é caracterizado por sedimentos de ambiente aluvionar, havendo grande variação em sua superfície freática em função dos regimes de chuva e das estações (Marques, 2010). Ações antrópicas, como bombeamento da água pelos moradores e a extração mineral em sua área de abrangência, influenciam na variação do lençol freático superficial da região. ${ }^{4}$

0 Rio Guandu recebe as águas do Rio Paraíba do Sul, a partir do sistema de transposição no Ribeirão das Lajes, originalmente pensado apenas para a produção de energia elétrica. 0 rio representa um relevante papel no abastecimento de toda a RMRJ, sendo a Estação de Tratamento de Água (ETA) controlada pela Cedae, localizada em sua margem leste, no município de Nova Iguaçu. A ETA garante o abastecimento de quase $80 \%$ da população fluminense, fornecendo água para cerca de nove milhões de habitantes. Entretanto, sua capacidade vem se restringindo gradativamente, e estudos recentes indicam que a vazão do Rio Guandu pode se reduzir tanto em função do avanço da água salobra (prisma de salinidade) em sua foz na Baía de Sepetiba, bem como com a ampliação das outorgas de utilização de águas doces para atender ao desenvolvimento industrial/urbano previsto (Coelho e Antunes, 2011), comprometendo o abastecimento de água na metrópole.

Além das questões acima, outros problemas ambientais ameaçam a produção hídrica do Guandu em função da expansão urbana e da ocupação do território, muitas vezes irregular, que extrapola a faixa não edificante de 500 metros em ambas as margens. Nessa faixa ocorre a extração de areia, atividade econômica intensa e lucrativa que vem causando irreversíveis danos ao ambiente e à paisagem local. Essa atividade de extração mineral vem progressivamente se ampliando, impactando o lençol freático da bacia de Sepetiba e, consequentemente, o Aquífero Piranema. 0 polo de extração mineral em ambiente de cava submersa é o maior do Estado do Rio de Janeiro e abastece a indústria da construção civil da RMRJ, gerando emprego e renda; entretanto, muitas das empresas areeiras atuam ilegalmente ou com registros e permissões vencidos. Um Termo de Compromisso de Ajustamento de Conduta (TAC), assinado por órgãos estaduais ligados ao ambiente e por sindicatos das mineradoras e representantes dos areeiros em 2003, com vistas à preparação de um Plano de Recuperação de Área Degrada (PRAD), teve pouco ou nenhum resultado. Mais de dez anos depois, pouco se vê no sentido da remediação ou recuperação das cavas abandonadas ou da mitigação dos impactos daquelas em operação.

Uma ação conjunta e a intensificação da fiscalização ${ }^{5}$ tornam-se urgentes, pois essa atividade econômica vem ocasionando irreversíveis impactos, descaracterizando a paisagem local e contaminando o superficial e frágil lençol freático (Marques, 2010). Planos de manejo e de recuperação ambiental definidos por agências governamentais foram realizados para o reaproveitamento das lagoas artificiais e uma das possibilidades seria a introdução da piscicultura, que vem sendo 
[...] uma das principais fontes de remediação de lagoas de mineração abandonadas no Brasil (...) Todavia, o alumínio pode ser o fator limitante da introdução da piscicultura nas cavas de extração de areia devido a sua disponibilidade na coluna d'água, ou seja, o alumínio se encontra dissolvido em ambientes ácidos, sendo, assim, tóxico para tais indivíduos. (Marques, 2010, p. 19)

Outro problema que atinge os dois principais corpos hídricos da região - tanto o Rio Guandu quanto o Aquífero Piranema - é a poluição proveniente das águas de seus afluentes, tais como o Rio dos Poços, um dos mais poluídos, e os córregos de Seropédica que, por sua vez, recebem efluentes do esgoto doméstico sem tratamento. Além disso, a falta de infraestrutura de drenagem de águas pluviais provoca alagamentos em vários trechos da planície aluvionar, seja nas áreas urbanas ou periurbanas, causando o carregamento de poluentes para os cursos d'água por meio da capilaridade natural do terreno.

Com a instalação em 2011 de um Centro de Tratamento de Resíduos Santa Rosa, em Seropédica, surge ainda a possibilidade de contaminação do Aquífero Piranema e o Rio Guandu, caso ocorra vazamento do chorume produzido pelo CTR, e ainda em função do alto índice pluviométrico de Seropédica, ainda que em estações específicas. Essa é uma constante preocupação de especialistas e acadêmicos que criticam sua localização sobre Bacia Sedimentar de Sepetiba e sobre o aquífero. Conforme pesquisa da Coppe, ${ }^{6}$ a transferência do aterro de Gramacho para Seropédica foi um equívoco logístico de médio e longo prazo. Estudos detalhados afirmam que "a área selecionada não é adequada à implantação de uma Central de Resíduos Sólidos". 0 estudo lista as principais "entidades afetadas: Aquífero Piranema, nascentes, proximidades de significantes referências geográficas, Campus da UFRRJ, cidade de Seropédica, e agrovilas" (Goes et al., 2011, p. 1). De modo análogo, moradores de suas proximidades e produtores locais reclamam do mau cheiro e dos insetos que proliferam, enquanto se intensifica a desvalorização de suas propriedades rurais.

Um agravante na questão hídrica local é a incipiente ocupação da região por empreendimentos habitacionais de interesse social ou condomínios fechados, que ocasionam direta ou indiretamente impactos ambientais na região. Estudos realizados no âmbito do grupo de pesquisas Gedur identificaram que um dos empreendimentos financiados pelo Programa Minha Casa Minha Vida (PMCMV) situa-se contíguo à Flona Mário Xavier. Ambos são cortados por um pequeno córrego que nasce nas escarpas da Serra de Paracambi e tem grande potencial paisagístico e recreativo, pelos serviços ambientais prestados e como corredor verde interligando outras áreas florestadas à Flona. Entretanto, o córrego vem sendo assoreado e recebe os efluentes da Estação de Tratamento de Esgotos (ETE) do condomínio, instalada em faixa de área de preservação permanente (APP) junto ao curso d'água. A ETE, que deveria tratar o esgoto residencial antes de seu deságue, não funciona adequadamente, estando desativada desde o início da ocupação do empreendimento, em fevereiro de 2013, até o momento da escritura deste artigo. A baixa altitude do sítio, 0 lençol freático superficial e o esgoto sem tratamento produzem valões a céu aberto nas vias internas do condomínio, e vem contaminando 
o córrego, que depois de atravessar a Flona deságua no Rio Guandu, a jusante da ETA, indicando uma importante fonte de contaminação. Algumas ações mitigadoras vêm sendo propostas pela administração da Unidade de Conservação Flona Mário Xavier, ${ }^{7}$ dentre elas projetos de educação ambiental envolvendo moradores e a população local.

Dos vários riscos ambientais identificados na análise realizada sobre o recorte regional, a ocupação urbana traz consigo demandas infraestruturais: abertura e pavimentação de vias, construção de edificações, seja formal ou informalmente, canalização e transposição de cursos d'água, entre outros, ocasionando, muitas vezes, a impermeabilização das superfícies. Consequentemente, o processo natural de infiltração das águas da chuva acaba por causar alagamentos e erosão. Há pouca ou nenhuma preocupação dos órgãos gestores das águas pluviais sobre a qualidade com que essas águas chegam aos rios ou seus afluentes. De forma geral, a infraestrutura de drenagem não está sendo planejada de maneira a obter eficiência e acaba por causar impactos negativos no solo e nos corpos hídricos. Essa realidade não é exclusiva nem da cidade de Seropédica, nem do recorte da Bacia Sedimentar de Sepetiba, refletindo a situação das cidades periféricas da RMRJ como um todo.

\section{Boas práticas de gestão das águas urbanas}

Estudos hidrológicos apontam para o reaproveitamento das águas pluviais e para os danos causados nas superfícies por onde passa, principalmente quando o excesso de água causa transtornos como alagamentos, erosão do solo, escorregamentos em encostas, contaminação das águas, engarrafamentos, dificuldades de locomoção e mobilidade, etc. Nesse contexto, novos conceitos de gerenciamento das águas provenientes do escoamento superficial em meio urbano vêm sendo aplicados e desenvolvidos em algumas cidades do mundo, nos últimos anos.

Técnicas inovadoras para projeto e gestão das águas pluviais urbanas podem proporcionar benefícios como:

- integração do tratamento de águas de chuva com a paisagem urbana, incorporação de múltiplos usos (reuso e uso eficiente da água) e a otimização do visual paisagístico e recreacional;

- proteção da qualidade da água do sistema de drenagem em áreas urbanas;

- redução do escoamento superficial e dos picos em áreas urbanas com emprego de medidas de detenção/retenção e minimização de áreas impermeabilizadas;

- valorização imobiliária e redução dos custos de infraestrutura do sistema de drenagem.

Uma das propostas possíveis para reduzir impactos ambientais da infiltração no solo das águas das chuvas sobre os recursos hídricos, antes que escoe superficialmente por áreas de maior densidade na cidade, é a definição de uma metodologia de projeto para destinação final das águas de escoamento superficial. Quando não devidamente destinadas, as águas pluviais tendem a se acumular nas vias e logradouros públicos, carreando os mais diversos tipos de contaminantes e prejudicando a qualidade dos corpos hídricos onde terminam por desaguar. 
Nesse sentido, na metodologia proposta foram considerados o tipo de solo, os dados climáticos regionais, o uso e a ocupação do solo urbano, a cobertura vegetal e a topografia. Tais aspectos geobiofísicos embasam as soluções pontuais de baixo custo com o objetivo de eliminar os alagamentos formados nos períodos de chuva, bem como mitigar os impactos sobre os recursos hídricos existentes.

A proposta foi elaborada para uma fração da rodovia BR-465, na parte central do município de Seropédica, o núcleo urbano conhecido como Km-49, cuja área perfaz $0,32 \mathrm{~km}^{2}$. Identificou-se o divisor de águas de sua bacia de contribuição. Foram utilizadas aquelas que contribuem diretamente com o excedente hídrico da fração da rodovia estudada.

\section{Cálculo do volume de excedente hídrico}

0 escoamento superficial desempenha um importante papel nas áreas com declive ou durante as chuvas pesadas, especialmente quando ocorre em superfície de solo seco. Esse valor pode ser estimado simplificadamente, por meio de um coeficiente apropriado para as características da cobertura superficial do sítio (tipo de material de cobertura e inclinação do talude) (Chow, 1964 apud Schueler, 2005), de acordo com a seguinte fórmula:

$$
R=C * P(1)
$$

Em que:

R: descarga do escoamento superficial ( $\mathrm{mm}$ )

C: coeficiente do escoamento superficial

P: precipitação pluviométrica $(\mathrm{mm})$

Tabela 1 - Comparação entre os coeficientes de escoamento superficial para áreas de drenagem com diferentes topografias, solo e condições de cobertura

\begin{tabular}{l|c|c|c|c|c|c|c|c|c}
\hline \multirow{2}{*}{\multicolumn{1}{c}{ Tipos de área }} & \multicolumn{8}{c}{ Coeficiente de escoamento superficial "C" } \\
\cline { 2 - 9 } & \multicolumn{3}{|c|}{ Inclinação < 2\% } & \multicolumn{2}{c}{ Inclinação > 2 e < 10\% } & \multicolumn{3}{c}{ Inclinação > 10\% } \\
\hline Solo descoberto (argila) & 0,60 & 0,60 & 0,60 & 0,66 & 0,70 & 0,70 & 0,70 & 0,82 & 0,80 \\
Argila ou silte & --- & 0,50 & 0,50 & -- & 0,60 & 0,60 & --- & 0,72 & 0,70 \\
Prado e pastagem (argila ou silte) & 0,25 & 0,30 & 0,35 & 0,30 & 0,36 & 0,45 & 0,35 & 0,42 & 0,55 \\
Cultivado/impermeável (argila) & 0,50 & 0,40 & 0,50 & 0,55 & 0,55 & 0,60 & 0,60 & 0,60 & 0,70 \\
Cultivado/permeável (areia) & 0,25 & 0,10 & 0,20 & 0,30 & 0,16 & 0,30 & 0,35 & 0,22 & 0,40 \\
\hline
\end{tabular}

Fonte: Blakey (1997 in IPT/Cempre, 2000). 
A literatura apresenta muitos relatórios de coeficientes de escoamento superficial padrão para diversas aplicações em engenharia. A Tabela 1 apresenta três exemplos de coeficientes de escoamento superficial baseados nos efeitos individuais da topografia, tipo de solo e vegetação de cobertura. A fórmula relaciona o escoamento superficial e a duração da chuva (ex. chuvas curtas resultam em molhar a superfície do solo e preencher as depressões superficiais/a proporção de infiltração decresce na medida em que o material de cobertura se torna molhado).

Para uma inclinação média maior do que $10 \%$ e a área de estudo com $323.000 \mathrm{~m}^{2}$, tem-se:

$$
R=0,70 \times 30=21 \mathrm{~mm} \text { ou } 0,021 \mathrm{~m}
$$

Assim, o volume do excedente hídrico no mês de janeiro, quando as chuvas ocorrem em maior volume, é estimado em $6.783 \mathrm{~m}^{3}$, que representa o volume de água que demanda destinação.

Em outro modo de fazer o cálculo considera-se:

$$
\mathbf{R}=\mathbf{I}-\mathbf{K}
$$

\section{Em que}

R: descarga de escoamento superficial (mm)

I: Intensidade Pluviométrica máxima $(\mathrm{mm} / \mathrm{h})$

$\mathrm{K}$ : Coeficiente de permeabilidade do solo $(\mathrm{cm} / \mathrm{s})$

e ainda
As intensidades médias dos picos das chuvas, segundo Carvalho et al. (2012) foram de $34 \mathrm{~mm} / \mathrm{h}, 28 \mathrm{~mm} / \mathrm{h}$ e $21 \mathrm{~mm} / \mathrm{h}$ para Seropédica. A permeabilidade do solo pode ser considerada de $10-5 \mathrm{~cm} / \mathrm{s}$.

Para:

$$
\begin{aligned}
& \mathrm{I}=28 \mathrm{~mm} / \mathrm{h} \text { tem-se } \\
& \mathrm{R}=28 \mathrm{~mm} / \mathrm{h}-0,36 \mathrm{~mm}(\text { ou } 105 \mathrm{~cm} / \mathrm{s})= \\
& 27,64 \mathrm{~mm} \\
& \mathrm{~V}=0,028 \mathrm{~m} \times 323000 \mathrm{~m} 2=9.044 \mathrm{~m}^{3}
\end{aligned}
$$

Observa-se que os valores de escoamento superficial calculados pelos dois métodos são muito parecidos, variando de aproximadamente 7 a $9 \mathrm{~m}^{3}$.

Foram mapeados os principais pontos de alagamento no recorte em estudo. A coleta de dados foi feita nos meses de janeiro e fevereiro de 2013, em período de intensa precipitação. Registraram-se três principais pontos da cidade que sofrem com alagamentos constantes, em ambas as margens da rodovia BR465 (Figura 3).

O solo da região de Seropédica tem seu horizonte superficial arenoso, de pouca espessura, o que possibilita uma rápida absorção da água da chuva. Porém, sob a superfície arenosa há uma camada espessa de solo de baixa permeabilidade. Dessa forma, o horizonte superficial satura rapidamente, e o excedente hídrico se aloca sobre a superfície, devido à dificuldade de se infiltrar pela camada inferior do solo (Figura 4). 
Figura 3 - Imagem aérea de Seropédica

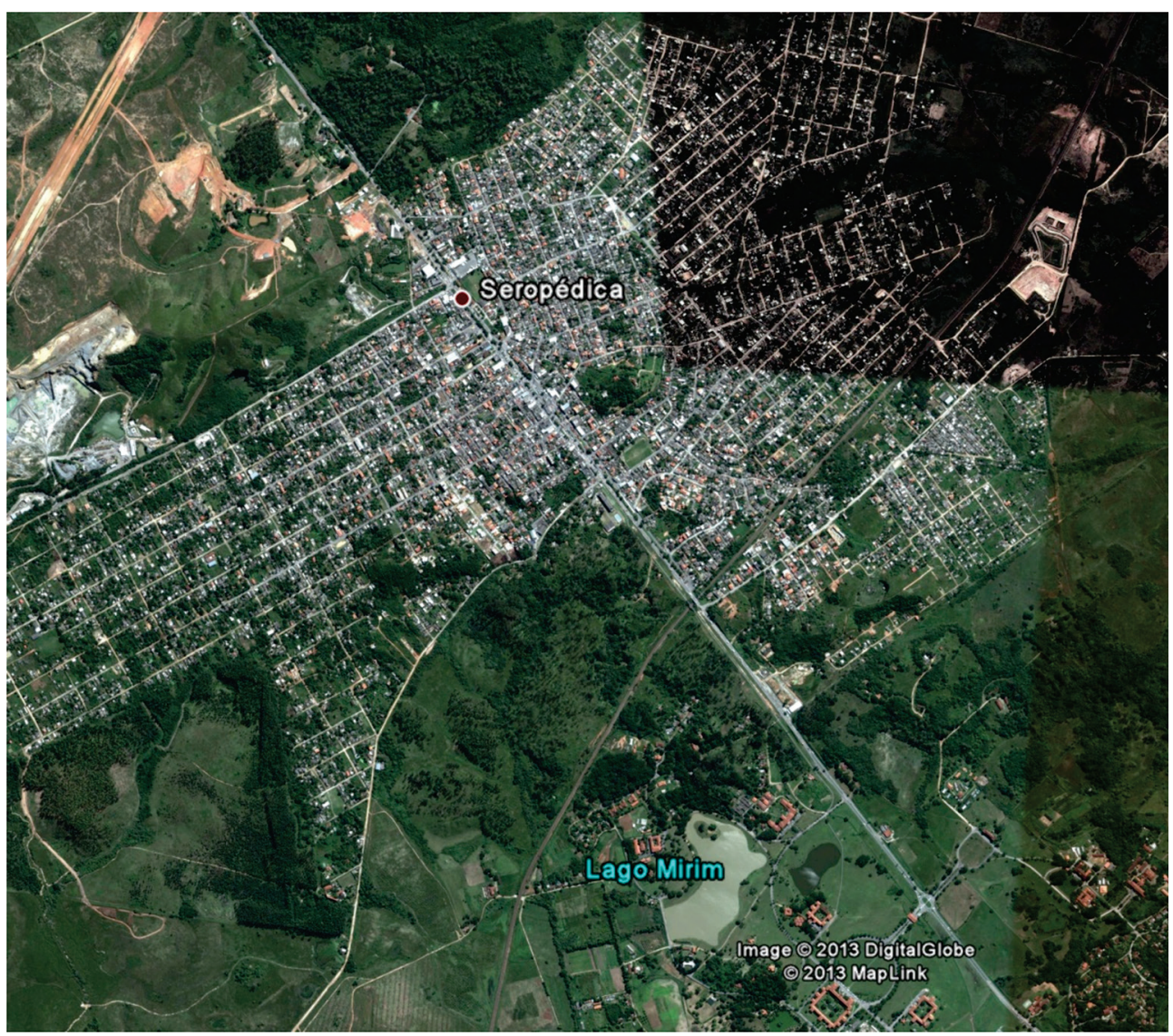

Fonte: Edição sobre imagem do Google Earth. 
Figura 4 - Ponto de alagamento 3 ao longo da rodovia BR 465

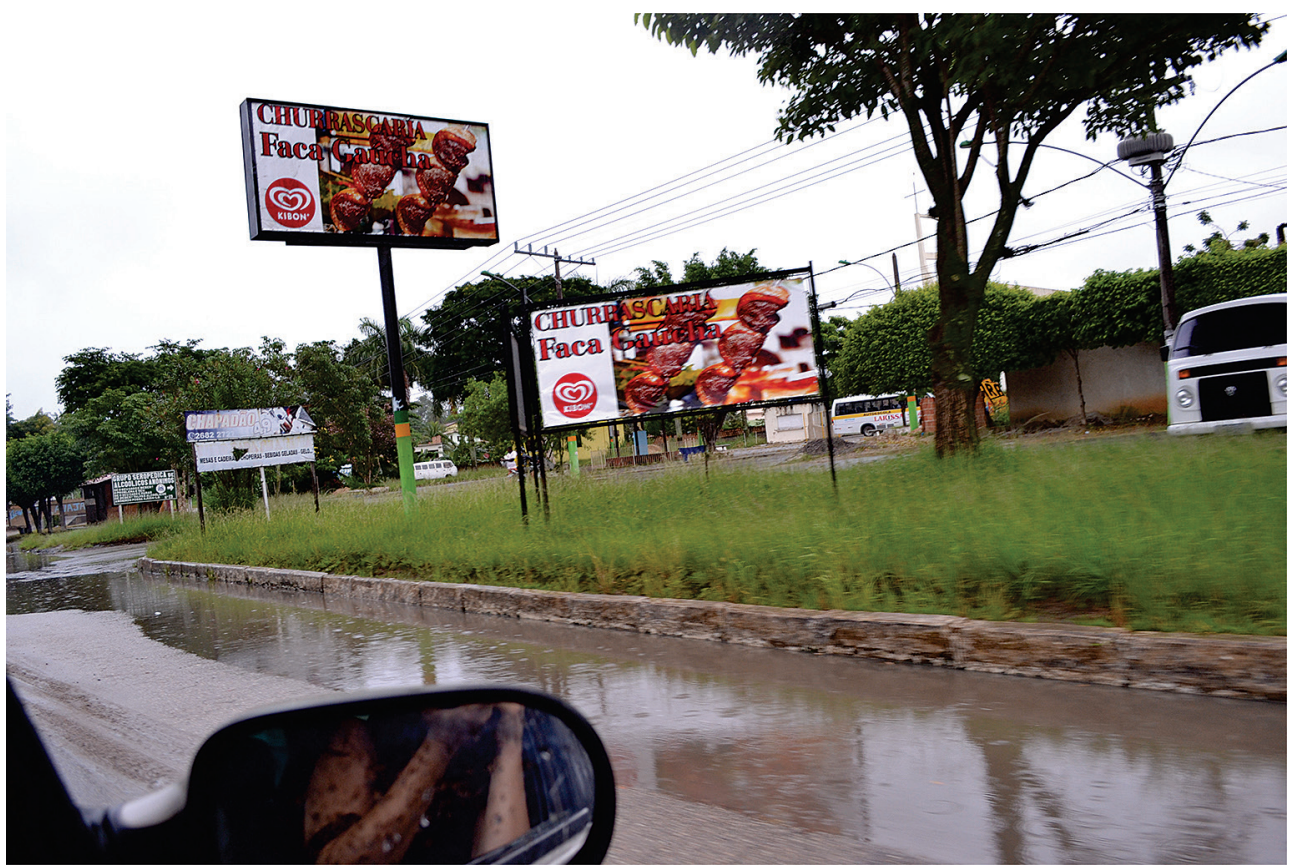

Fonte: acervo dos autores.

No sentido de reduzir os alagamentos ao longo das vias, possibilitar a melhoria da qualidade urbana e mitigar impactos sobre os recursos hídricos da região, uma das soluções possíveis é o paisagismo rodoviário, que deve ser adequado às características típicas da paisagem regional. Para a especificação coerente das espécies de plantas, deve-se avaliar questões de segurança, tais como, percepção de distâncias adequadas para evitar a criação de obstáculos visuais e cuidado com os raios de curvatura para que não haja ilusão de ótica por parte dos motoristas. A disposição volumétrica das espécies vegetais contribui, em determinadas situações, para a segurança na rodovia, conduzindo a atenção do motorista para a pista e evitando sua distração e a formação de áreas de sombra isoladas ou descontínuas.

No caso da área em estudo, optou-se por espécies arbustivas para a composição de canteiros, por questões como a segurança do usuário da via, em caso de impacto e pela não obstrução da visibilidade. Em função do clima tropical quente da região, a escolha recaiu sobre uma espécie popularmente conhecida como Buxinho, ou Buxus sempervirens, muito utilizado em paisagismo rodoviário devido à densidade das folhas e facilidade das podas e baixa manutenção. Dessa forma, torna-se possível a efetiva melhoria na paisagem da cidade com a implantação de canteiros urbanos, trazendo melhor qualidade de vida para 
os usuários e reduzindo a ocorrência de alagamentos durante os meses de verão.

Pelo fato de a BR-465 ser uma rodovia federal, buscou-se evitar grandes alterações em seu traçado e alinhamento, respeitando as regras estabelecidas pelo Departamento Nacional de Infraestrutura de Transportes (DNIT) e o Departamento de Estradas de Rodagem (DER). Assim, a proposta de intervenção local limitou-se a indicar uma solução simples e eficiente, para a destinação do excedente hídrico.

Foi planejada a criação de jardins de infiltração ao longo da rodovia de modo que o excedente hídrico seja direcionado a eles e possa se infiltrar lentamente no sol sem causar distúrbios no trânsito de pedestres e o tráfego viário. Sua localização deve ser próxima aos pontos de alagamentos identificados e próximos à borda da pista de rolamento a uma distância máxima de 4,5m (Manual de Sinalização Rodoviária do DER/SP) (Figura 5).

Os jardins plantados com espécies vegetais arbustivas nativas, não apenas agilizam a infiltração das águas no solo, mas, favorecem tanto a paisagem local, bem como a ambiência urbana. Além disso, objetivam reorientar o caminho das águas pluviais, aumentando a espessura do fundo drenante, de modo que, em vez de alagamentos, as águas se infiltrem rapidamente nos jardins plantados. Assim evita-se o empoçamento das águas que são direcionadas com melhor qualidade ao subsolo. Importante mencionar que tal solução é viável técnica e economicamente, não demandando elevados custos financeiros, nem os transtornos que grandes obras trazem aos centros urbanos.

Figura 5 - Detalhe do Jardim de Chuva a ser instalado ao longo da rodovia

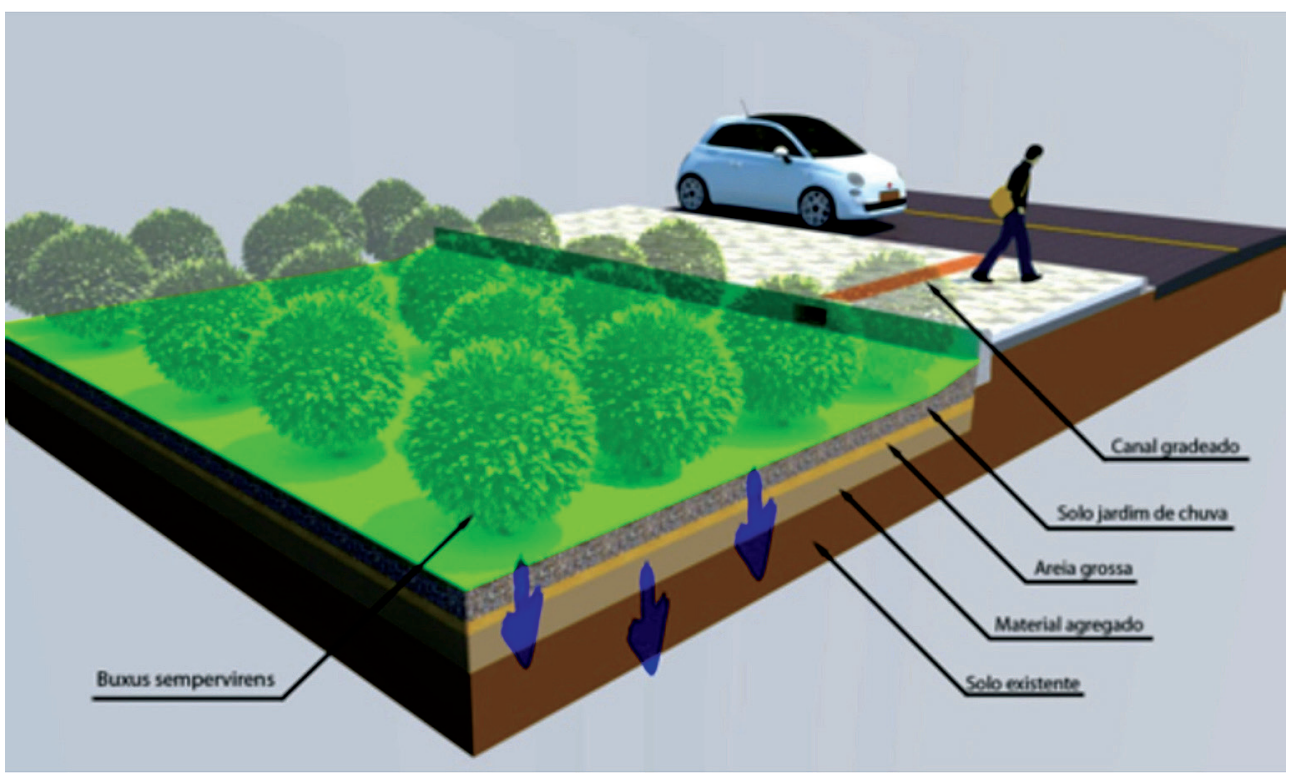

Fonte: Carvalho, J. et al. (2014). 


\section{Considerações finais}

Na medida em que aprofundamos a investigação em nível regional e local sobre a Bacia Sedimentar de Sepetiba que abrange o objeto desse estudo, o município de Seropédica, fica cada vez mais patente a necessidade de identificarmos suas potencialidades e fragilidades, no que tange ao crescimento econômico que se abate sobre a região. Grandes projetos de investimentos vêm possibilitando o crescimento econômico da região, mas também trazem consigo transformações e impactos que não se limitam ao âmbito municipal.

Dentre os diversos aspectos e características diagnosticados nesse estudo, torna-se importante dar ênfase às condicionantes geobiofísicas presentes, quanto ao solo, clima, topografia, cobertura vegetal e mesmo geomorfologia. Esses elementos determinam a paisagem que dá suporte às ações antrópicas e deve ser o ponto de partida de qualquer plano ou projeto, seja para desenvolvimento econômico da região, seja para a proteção ou preservação de seu ambiente natural.

A análise dos recursos hídricos presentes na Bacia Sedimentar de Sepetiba faz parte de um estudo socioambiental maior que integra a identificação de unidades paisagísticas, a caracterização e categorização dos espaços livres de urbanização e edificações, a análise da morfologia da paisagem e a proposição de cenários prospectivos sobre o futuro da região. Nesse sentido, os principais corpos hídricos existentes, o Rio Guandu e seus afluentes e o Aquífero Piranema, foram analisados na escala regional e configuram-se determinantes na questão do abastecimento de água em nível metropolitano. Ambos encontram-se ameaçados ambientalmente, em função das atividades econômicas e de extração mineral, de ocupações e expansão urbana formal e informal. Tanto a contaminação hídrica, quanto uma possível escassez, com a diminuição da vazão do rio ou pelo avanço da salinidade, poderão causar sérios danos ao abastecimento de água de toda a região metropolitana.

Em nível local, a falta de planejamento e a ausência ou precariedade de infraestrutura urbana, tais como drenagem pluvial e saneamento básico, vêm gerando transtornos à vida urbana, bem como podem vir a contaminar os cursos d'água, prejudicando ainda mais a qualidade hídrica regional. Como alternativa para mitigar ou reduzir tais impactos, são propostas soluções ambientalmente sustentáveis e economicamente viáveis, tais como os canteiros de chuva ao longo da rodovia, que podem ser aplicadas em situações similares em outras partes da Região Metropolitana.

Finalmente, esperamos ter contribuído com a disseminação da investigação em curso, ampliando a discussão sobre a franca transformação de municípios influenciados pelo arco rodoviário e trazendo à luz as ameaças que se abatem sobre os importantes recursos hídricos da Bacia Sedimentar de Sepetiba. Buscamos oferecer insumos e dados quantitativos e qualitativos que pretendemos aprofundar na busca de uma ação participativa, junto aos órgãos e agências municipais e regionais de planejamento, projeto e gestão, no sentido de propor diretrizes para a revisão do Plano Diretor Municipal. 


\section{Denise de Alcântara}

Universidade Federal Rural do Rio de Janeiro, Departamento de Arquitetura e Urbanismo e da PósGraduação em Desenvolvimento Territorial e Políticas Públicas. Seropédica/RJ, Brasil. denisedealcantara@gmail.com

\section{Adriana Soares de Schueler}

Universidade Federal Rural do Rio de Janeiro, Departamento de Arquitetura e Urbanismo e Pós Graduação em Desenvolvimento territorial e Políticas Públicas. Seropédica/RJ, Brasil. schueler.a@gmail.com

\section{Agradecimentos}

Os autores agradecem a colaboração dos alunos de graduação Bianca Trindade, Jackson Carvalho e Joana Freitas (bolsistas I. C.) e Vinícius Perrut dos Santos (mestrando PPGDT/UFFRJ) do desenvolvimento da pesquisa de campo; ao CNPq e Faperj pelas bolsas de Iniciação Científicas concedidas; à Faperj pela bolsa de Apoio à Pesquisa Básica APQ-1. Agradecemos ainda o apoio do Grupo Sistemas de Espaços Livres do Rio de Janeiro (SEL-RJ) e do Programa de Pós-Graduação em Desenvolvimento Territorial e Políticas Públicas (PPGDT) da Universidade Federal Rural do Rio de Janeiro pela acolhida da proposta de pesquisa e disponibilização de infraestrutura para seu desenvolvimento.

\section{Notas}

(1) Instituída pela Lei Complementar n. 20, de 10 de julho de 1974 e após diversas alterações e inclusões, atualmente a RMRJ é formada pelos municípios: Rio de Janeiro, Belford Roxo, Duque de Caxias, Guapimirim, Itaboraí, Japeri, Magé, Maricá, Mesquita, Nilópolis, Niterói, Nova Iguaçu, Paracambi, Queimados, São Gonçalo, São João de Meriti, Seropédica, Tanguá, Itaguaí, Rio Bonito e Cachoeiras de Macacu.

(2) A pesquisa recebe Apoio à Pesquisa Básica (APQ-1 - Processo E-26.110.397/2014) da Faperj

(3) Ambos os grupos, Gedur e EcoCidades, são certificados pelo Diretório de Pesquisas do CNPq.

(4) Para visualizar mapa da bacia hidrográfica do Rio Guandu, com indicação da localização e extensão do Aquífero Piranema, entre Itaguaí e Seropédica ver: SINAGEO; disponível em: http://www. sinageo.org.br/2012/trabalhos/8/8-305-529.html 
(5) Apesar da fiscalização, as interdições não impedem a atividade. Ver reportagens do Globo de agosto/2011, disponível em: http://oglobo.globo.com/rio/secretaria-do-ambiente-fecha-areaisilegais-prende-cinco-pessoas-em-seropedica-2685942 e de fevereiro/2013 - "Blitz interdita quatro areais clandestinos em Seropédica", disponível em http://www.rj.gov.br/web/sea/ exibeconteudo?article-id=1451901.

(6) Depoimento de Cícero Pimenteira, pesquisador da Coppe, relativo a sua investigação sobre o Centro de Tratamento de Resíduos Santa Rosa. Disponível em http://www.planeta.coppe.ufrj. br/artigo.php?artigo $=1289$

(7) Conforme entrevista informal concedida por Andrea de Nóbrega Ribeiro às autoras em junho de 2013.

\section{Referências}

ALCANTARA, D. (2014). “A paisagem em transformação: o planejamento do território como catalisador do equilíbrio entre desenvolvimento econômico e socioambiental em Seropédica". In: ABATE, C. e KAROL, J. L. (orgs.). UPE11 Conducir las transformaciones urbanas. Libro Digital - Tomo 1 Trabajos Completos. La Plata, Universidade Nacional de La Plata.

ARAÚJO, R. C. L. (2011). A Universidade no Contexto Urbano: As representações presentes na relação socioespacial entre a Universidade Federal Rural do Rio de Janeiro e a cidade de Seropédica. Tese de Doutorado. Rio de Janeiro, Universidade Federal do Rio de Janeiro.

CARVALHO, D. F.; MONTEBElLER, C. A.; FRANCO, E. M. e BERTOL, I. (2005). Padrões de precipitação e índices de erosividade para as chuvas de Seropédica e Nova Friburgo, RJ. Revista Brasileira de Engenharia Agrícola e Ambiental. Campina Grande/PB, v. 9, n. 1, pp. 7-14. Disponível em: http:// www.agriambi.com.br/revista/v9n1/index.htm. Acesso em: 28 out 2014.

CARVALHO, J.; FREITAS, J.; SANTOS, V. e SCHUELER, A. (2014). Propostas para redução de alagamentos por água de chuva em Seropédica. In: REGSA. Anais, v. 1, pp. 333-359. Florianópolis, UFSC.

COELHO, F. M. e ANTUNES, J. C. O. (2011). Balanço hídrico da Bacia Hidrográfica do Rio Guandu com a expansão prevista do abastecimento público da Região Metropolitana do Rio de Janeiro. In: XIX SIMPÓSIO BRASILEIRO DE RECURSOS HÍDRICOS. Anais. Maceió, UFAL.

FORMAN, R. (2008). Urban regions: ecology and planning beyond the city. Cambridge, Cambridge University Press.

GOES, M. H. B.; XAVIER-DA-SILVA, J. e MARINO, T. B. (2011). Depoimento Técnico-Científico sobre o Aterro Sanitário na Baixada de Sepetiba, RJ. Disponível em: http://www.sinageo.org.br/2012/ trabalhos/8/8-305-529.html. Acesso em: 22 abr 2014.

HARVEY, D. (2011). O enigma do capital: e as crises do capitalismo. São Paulo, Boitempo.

IPT/CEMPRE (2000). Lixo municipal: manual de gerenciamento integrado. São Paulo, Instituto de Pesquisa Tecnológicas/IPT. 
MAGNOLI, M. (2006). Em busca de 'outros' espaços livres de edificação. Paisagem Ambiente: ensaios. São Paulo, FAUUSP, n. 21, pp. 141-174.

MARQUES, E. D. (2010). Impactos da mineração de areia na Bacia Sedimentar de Sepetiba, RJ: estudo de suas implicações sobre as águas do Aquífero Piranema. Tese de Doutorado. Niterói, Universidade Federal Fluminense.

MONTEIRO, J. C. C. (2010). Rede de Avaliação e Capacitação para Implementação dos Planos Diretores Participativos. Disponível em: http://www.observatoriodasmetropoles.ufrj.br/seropedica.pdf. Acesso em: 18 abr 2014.

MONTEZUMA, R. C. M. e CINTRA, D. (2012). “O Arco Metropolitano: um marco da transformação da paisagem". In: TÂNGARI, V.; RÊGO, A. e MONTEZUMA, R. (orgs.). O Arco Metropolitano do Rio de Janeiro - Integração e fragmentação da paisagem metropolitana e dos sistemas de espaços livres de edificação. Rio de Janeiro, PROARQ-UFRJ.

OLIVEIRA, F.; CARDOSO, A.; COSTA, H. S. M. e VAINER, C. (orgs.) (2012). Grandes Projetos Metropolitanos: Rio de Janeiro e Belo Horizonte. Rio de Janeiro, Letra Capital.

SANTOS, M. (2005). Da Totalidade ao Lugar. São Paulo, Edusp.

SCHUELER, A. S. (2005). Estudo de caso e proposta de avaliação de áreas degradadas por disposição de resíduos sólidos urbanos. Tese de Doutorado. Rio de Janeiro, Universidade Federal do Rio de Janeiro.

SEROPÉDICA (2006). Plano Diretor Participativo do Município de Seropédica. Lei 328/06, de 3/9/2006. Seropédica, Prefeitura Municipal de Seropédica.

TÂNGARI, V. R.; REGO, A. Q. e MONTEZUMA, R. de C. M. (orgs.) (2012). O Arco Metropolitano do Rio de Janeiro: Integração e fragmentação da paisagem metropolitana e dos sistemas de espaços livres de edificação. Rio de Janeiro, PROARQ-UFRJ.

TÂNGARI, V. R; ANDRADE, R. e SCHLEE, M. B. (orgs.) (2009). Sistema de espaços livres: o cotidiano, ausências e apropriações. Rio de Janeiro, PROARQ-UFRJ.

Texto recebido em 8/ago/2014

Texto aprovado em 15/nov/2014 